\title{
36. The Sister Chromatid Exchange and the DNA Repair Replication in Human Chromosomes
}

\author{
By Yukimasa SHIRAISHI \\ Department of Anatomy, Kôchi Medical University, \\ Nangoku-shi, Kôchi 781-51
}

(Communicated by Sajiro Makino, M. J. A., April 12, 1978)

The involvement of DNA-repair in the formation of sister chromatid exchanges (SCEs) has excited our interest, because of several recent reports which suggest that SCEs are related to the error of DNA-repair mechanisms (Kato 1974; Latt 1974). The incidence of SCEs is a very sensitive indicator on the exposure to chemical mutagens involving DNA damage, while recent studies by Shiraishi et al. (1977) and Galloway (1977) have shown that the formation of SCEs is not necessarily associated with chromosome aberrations. In contrast, the findings of Kihlman (1975) and Shiraishi (1977) have suggested, based on the lack of the caffeine effect and also of single strand exchanges in SCEs, that the mechanism of the SCE is related most likely to exchanges of the double-strand of a DNA duplex in each chromatid, but not associated with a caffeine-sensitive post-replication repair for DNA damage. It is therefore of importance to inquire into the possible association of SCEs with cellular DNAexcision repair processes. The author undertook a comparative study on the excision repairability (unscheduled DNA synthesis) in relation to the yields of SCEs induced by chemicals, in view of that it might be effective in elucidating the mechanism of an increased SCE formation.

Materials and methods. The study was carried out with a normal human male lymphoid cell line. The method of establishing lymphoid cell-line followed the established technique of Minowada et al. (1972). The cell-line was maintained in the RPMI1640 medium supplemented with $10 \%$ heat-inactivated fetal calf serum and antibiotics (100 $\mathrm{U}$ penicillin $/ \mathrm{ml}$ and $50 \mu \mathrm{g}$ streptomycin $/ \mathrm{ml}$ ) at $37^{\circ} \mathrm{C}$. The generation time (cell-cycle time) of the cell-line was approximately 23 hours. Cytogenetically the cell-line was characterized by a normal diploid chromosome constitution. In order to induce the SCE, the cultures were treated with mitomycin C (MMC) and $4 \mathrm{NQO}$ at $1 \times 10^{-7} \mathrm{~g} / \mathrm{ml}$ for $48 \mathrm{hrs}$ (two cell generations) in the presence of BrdU $5 \times 10^{-6} \mathrm{~g} / \mathrm{ml}$ in total darkness. For the differential sister chromatid staining of the chromosomes the method of Wolff et al. 
(1974) was efficiently applied. For the study of unscheduled DNA synthesis (USD), the normal lymphoid cell-line was exposed to $4 \mathrm{NQO}$, methyl-methanesulphonate (MMS) and MMC for 90 min. at $5 \times 10^{-5} \mathrm{M}$, and then it was washed twice with the fresh medium and incubated in the prewarmed medium containing $10 \mu \mathrm{Ci} / \mathrm{ml}{ }^{3} \mathrm{H}$-thymidine (spec. act. $12.6 \mathrm{Ci} / \mathrm{mM}$ ) for $2 \mathrm{hrs}$. Cells were then fixed with the $3: 1$ methanolacetic acid mixture, coated with autoradiographic emulsion (Sakura NR-M2), and developed after 3 week-exposure. In each sample more than 150 non-S nuclei were selected for counting. The degree of repair synthesis was estimated by counting the number of grains over non-S nuclei (including mitosis) in them. The measurements of the SCE breakpoints were made in 20 normal cells treated with MMC and $4 \mathrm{NQO}$ by plotting the relative site of each exchange based on its distance from the centromere. For the analysis of distributions of USD grain counts in 4 NQO treated-normal cells, the arm of each chromosome was divided into 10 equal segments, and the grains on individual segments were counted. The measurements of the SCE breakpoint and the grain-distribution were made only in chromosome No. 1.

Results and discussion. The average frequencies of the normal lymphoid cell-line exposed to $1 \times 10^{-7} \mathrm{~g} / \mathrm{ml}$ of $4 \mathrm{NQO}$ and MMC in the $48 \mathrm{hr}$-culture were 28.5 and 55.3 SCEs per cell, respectively. They were about 6 to 10 times as high as the control frequency which was shown as 5.4 SCEs per cell in an average. The distribution of the SCE breakpoint was examined in chromosome No. 1 in cells treated with MMC and 4NQO. In Figs. $1 \mathrm{~A}$ and $1 \mathrm{~B}$ are shown the distribution and the frequency of the SCE per chromosome segment. The distribution of the SCE within chromosomes was apparently nonrandom, rarely involving the centromeric area in MMC- and 4NQO-treated normal cells. The unscheduled uptake of ${ }^{3} \mathrm{H}$-thymidine following the treatment with MMC, MMS and 4 NQO for 90 minutes at $5 \times 10^{-5} \mathrm{M}$ is shown in Fig. 2. Silver grains were detected in the nuclei of non-S nuclei (G1, G2 and mitotic cells), as well as in the $\mathrm{S}$ phase nuclei. The MMC-treated cells $\left(5 \times 10^{-5} \mathrm{M}\right)$ showed no remarkable change in the USD level in contrast to the increase of the SCE. As seen in Fig. 2, there was no difference in the amount of USD between the samples treated with MMS and 4NQO. The evidence indicates that USD operates on metaphase chromosomes as a whole in spite of their specificially condensed and multifolded structure. As seen in Fig. 3, all the chromosomes were labeled by USD at metaphases, suggesting that the amount of USD lies proportionally to the length of chromosomes, or corresponding to the amount of chromosomal DNA. The intra-chromosomal localization of grains in chromosome No. 1 was compared to that of the SCE breakpoint (Figs. 1A, 1B 


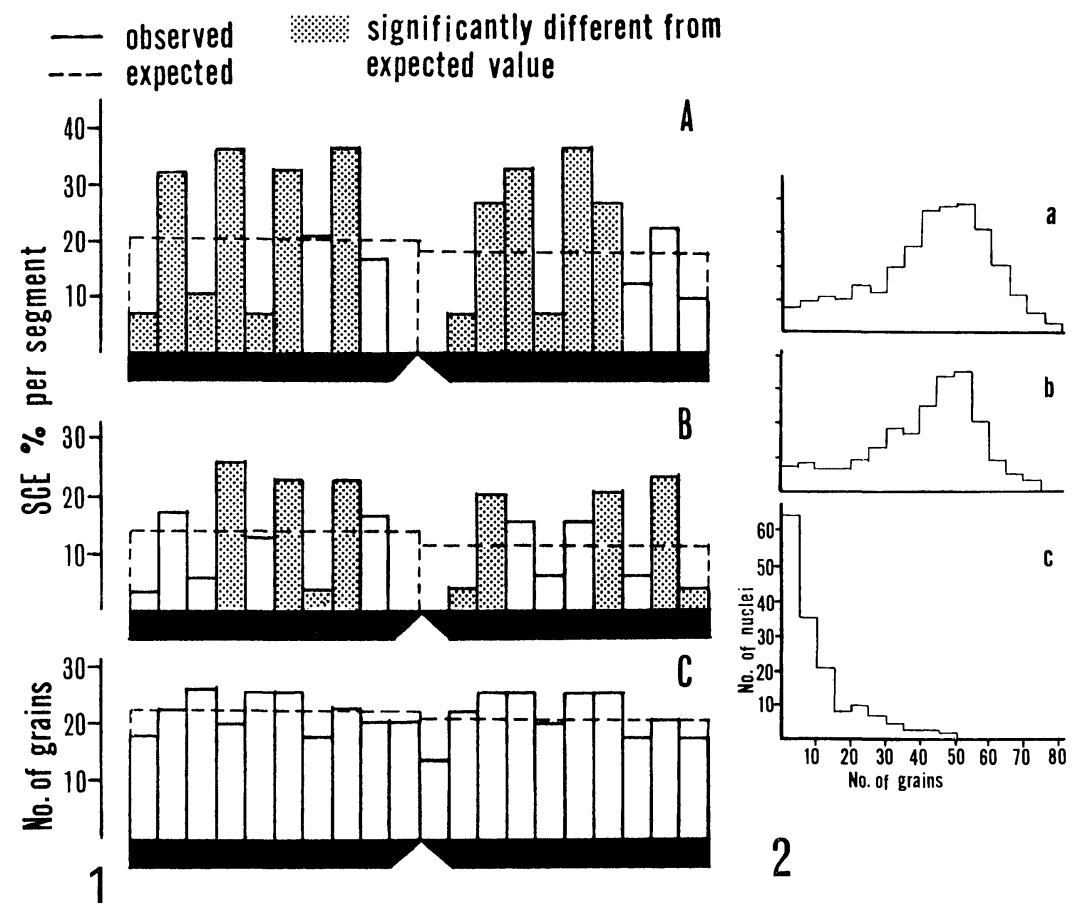

Fig. 1. Showing the distribution of SCE breakpoints induced by MMC(A) and $4 \mathrm{NQO}(\mathrm{B})$ compared with that of localization of USD grains induced by $4 \mathrm{NQO}(\mathrm{C})$. The SCE distribution was nonrandom, while the silver grain distribution is random over the chromatids. The shaded columns are segments containing an excess or deficiency of SCE which differ significantly from the expected value $(\mathrm{P}<0.05)$ by chi-square testing.

Fig. 2. Unscheduled uptake of ${ }^{3} \mathrm{H}$-thymidine by non-S phase cells following $4 \mathrm{NQO}(\mathrm{a}), \mathrm{MMS}(\mathrm{b})$ and MMC(c) treatments. The USD-level showed no detectable change after the MMC treatment.

and $1 \mathrm{C}$ ), and the silver grains were found distributed randomly over the chromatids in cells treated with $4 \mathrm{NQO}$, in contrast to the distribution of SCE. There were neither significantly grain-rich nor grainpoor segments in the chromosome, being not correspondent to the Gbanding pattern (Fig. 3). The feature indicates no close relation between the SCE breakpoint and USD grain distribution. On the above basis the conclusion is possible that the genesis of SCE is independent of the excision repair mechanism, and further that the mechanism of the SCE formation can not be interpreted by means of a simple concept involving the DNA repair mechanism. Evidently there are many questions remained unanswered for the SCE mechanism. The present findings suggest the importance of some other repair processes for the SCE formation. Knowledge is to be requested on the molecular basis in relation to the SCE, before the establishment 


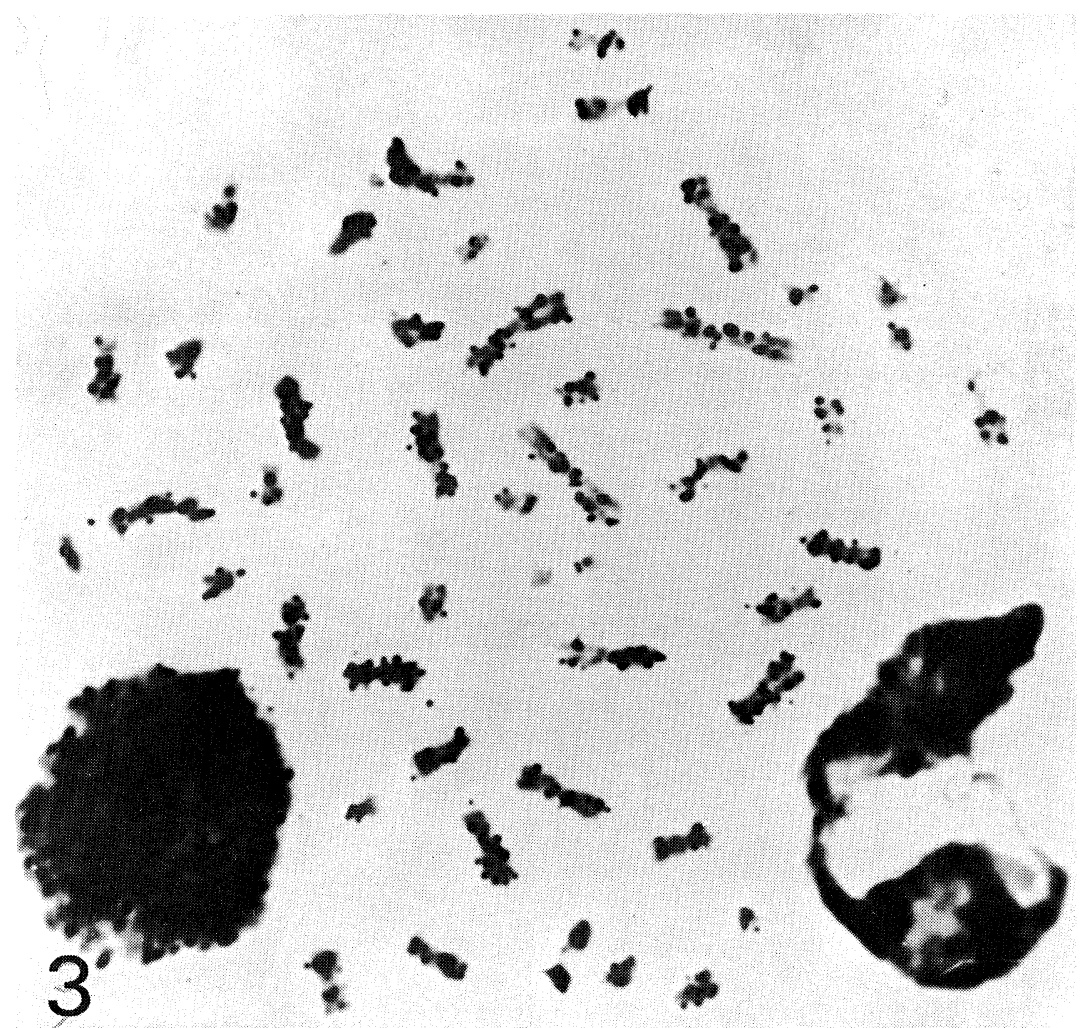

Fig. 3. Metaphase chromosomes from normal lymphoid cell-line, labeled by 4NQO-induced unscheduled DNA synthesis.

of a clear picture on the above problem. Further investigations are now in progress by the author along this line.

Acknowledgments. The author's sincere thanks are due to Emeritus Professor Dr. Sajiro Makino, M. J. A., for his expert advice and going over the manuscript. The work was supported in part by grant for Cancer Research from the Ministry of Education of Japan (NO. 201001).

\section{References}

Kato, H. (1974) : Exp. Cell Res., 85, 239-247.

Latt, S. A. (1974) : Proc. Natl. Acad. Sci. (Wash.), 71, 3162-3166.

Shiraishi, Y., and Sandberg, A. A. (1977) : Cytogenet. Cell Genet., 18, 13-23.

Galloway, S. M. (1977) : Mutat. Res., 45, 343-349.

Kihlman, B. A. (1975) : Chromosoma (Berl.), 51, 11-18.

Shiraishi, Y. (1977) : Proc. Japan Acad., 53, 226-230.

Minowada, J., Ohnuma, T., and Moore, G. E. (1972) : J. Natl. Cancer Inst., 49, 891-895.

Wolff, S., and Perry, P. (1974) : Chromosoma (Berl.), 48, 341. 